\title{
Carolina Stefoni sobre situación de los derechos de las personas migrantes en Chile
}

\author{
Abril Silva \\ Universidad de Chile \\ Benjamín González \\ Universidad de Chile
}

Chile se ha transformado en un importante destino de las migraciones en la región, en contraste con lo que sucedía décadas anteriores. Según los resultados del Censo de 2017, el porcentaje de inmigrantes, esto es, nacidos en el extranjero que declararon residir habitualmente en Chile al momento de ser censados, aumentó desde o,8\% en 1992 (105.070 personas) hasta el 4,35\% en 2017 ( 746.465 personas).

De los inmigrantes internacionales censados, $66,7 \%$ declaró haber llegado a Chile entre 2010 y 2017 , principalmente a partir de 2016 y hasta el día del censo (19 de abril de 2017). Del total de la población inmigrante, el 50,7\% proviene de tres países de América Latina: Perú (25,3\%), Colombia (14,2\%) y Venezuela (11,2\%).

La llegada dentro de corto tiempo de importantes flujos migratorios de extranjeros provenientes de Venezuela, producto de los conflictos políticos y su situación socioeconómica, ha ocasionado una demanda de ingreso al país que no ha sido anticipada por las autoridades. De esa manera, en los puestos de frontera en el norte se está comenzando a desarrollar una verdadera crisis humanitaria, de apariencia similar a lo que nos hemos acostumbrado a ver en las fronteras de Europa o de Estados Unidos, con importantes conjuntos de población muy vulnerable buscando su ingreso, incluidas muchas mujeres y niños que corren riesgos, que duermen a la intemperie y sin mayor asistencia, sin que se les permita su entrada a Chile.

Si bien en abril de 2018 se estableció la «visa de responsabilidad democrática» para los venezolanos - que otorga un permiso de residencia temporal por un año, prorrogable por una vez y que posibilita luego pedir la residencia definitiva-, esta visa ha terminado creando un estatuto totalmente diferente. La visa de responsabilidad democrática se ha solicitado por cerca de 97.000 personas, a los cuales se les han 
entregado aproximadamente 35.000 visas. En Chile ya se encuentran en la actualidad 288.333 personas venezolanas en condición de refugio, según las cifras de la Agencia de la ONU para los Refugiados (ACNUR).

Las políticas del gobierno se han endurecido para controlar la inmigración venezolana. El pasado 22 de junio de 2019, el gobierno chileno estableció la exigencia de una visa de turismo consular para aquellos ciudadanos venezolanos que quieran ingresar como turistas al país, fundándose en que los venezolanos venían principalmente con ánimos de avecindarse y no de hacer turismo. La tasa de rechazo en la frontera era superior al $40 \%$ de las solicitudes de ingreso de los venezolanos.

En nuestro país aún siguen vigentes los marcos normativos de los años noventa para la regulación de las migraciones. Recién se acaba de aprobar en la Comisión de Derechos Humanos del Senado la idea de legislar una nueva ley de migraciones y extranjería.

Para revisar el estado general de los derechos humanos de las personas migrantes en este contexto, hemos entrevistado a la profesora Carolina Stefoni Espinoza, en la actualidad directora de la carrera de Sociología de la Universidad Alberto Hurtado, Chile, y licenciada en Sociología de la Pontificia Universidad Católica de Chile. En sus estudios ha cursado el Magíster en Estudios Culturales en la Universidad de Birmingham, Inglaterra, y el Doctorado en Sociología en la Universidad Alberto Hurtado.

En abril del 2018, el gobierno ingresó un conjunto de modificaciones al proyecto de ley de migración y extranjería. ¿Considera que dichas indicaciones representan un esfuerzo bien encaminado por hacer una modificación normativa, administrativa y de políticas públicas con un enfoque de derechos?

No, hay varias indicaciones que nosotros hemos venido reforzando en la línea de que no es algo que consideremos que vaya a mejorar la situación de la migración y de los migrantes. Para mí, el tema clave es la prohibición del cambio de visa que se establece dentro del territorio chileno. En ese sentido, el proyecto da cuenta de una naturaleza mucho más restrictiva de la migración y de querer, a través de un sistema administrativo, restringir el ingreso de personas.

Ahora, en conjunto con el ingreso del proyecto, el Ejecutivo estableció a través de decreto una serie de decisiones que apuntan en la misma dirección de la ley, es decir, que no quiso esperar la discusión en el parlamento e incluyó lo de las nuevas visas, cambios y transformaciones. Ha sido interesante el efecto que han tenido esas propuestas de visas, y eso nos permite argumentar en el proyecto de ley que en realidad no resuelve para nada la situación migratoria, más bien la complejiza. En el caso de la migración para personas calificadas, han sido muy pocos los que han presentado solicitudes. Todas estas medidas apuntan a una imagen de migración que no tiene nada 
que ver con la realidad chilena, que se trata de una migración laboral, latinoamericana. Se tiene al modelo canadiense en vista, pero la realidad chilena es bien distinta a la realidad canadiense en todo sentido.

Lo que se hizo a través de decreto no ha resultado porque no da cuenta de que estas visas de responsabilidad democrática generaron una expectativa gigante. Han sido 20.000 las que se han entregado y hay alrededor de 90.000 solicitudes. Además, está la contradicción de que, cuando la gente viene por tierra y pide refugio, no se les otorga. El discurso humanitario es bien incongruente y la gente por supuesto sigue entrando como turista. No pueden esperar todo ese tiempo para que les otorguen las visas. Las otras visas también han sido muy selectivas, para una población ultracalificada.

¿Qué necesidades de modificación normativa no aborda el proyecto de ley?

No soy abogada, pero creo que es complicado que aquellos derechos asociados al cargo o al gasto fiscal no se otorguen, si las personas tienen la residencia y obtienen la visa, estando trabajando. ¿Por qué hay que esperar dos años para que se reconozcan esos derechos? Me parece que ahí se atenta contra el principio de igualdad. Creo que hay que hacer muchos más esfuerzos para asegurar el principio de igualdad y los derechos humanos de las personas en todo el territorio.

Esta es una ley más bien de ingreso de personas, que establece las condiciones de ingreso, pero no es propiamente una política migratoria. Se esperaría que hubiese más espacios de participación para la sociedad civil, de la academia, de los distintos ministerios sociales, del Consejo de Política Migratoria. Se trata de una discusión que requiere muchos actores y la ley en el fondo no permite una participación más amplia de los actores relevantes en ese tipo de decisiones. Creo que falta más profundidad en la estructura que entrega para la participación en lo que es la definición de la política.

¿Podría profundizar en la línea de que es una ley más bien de ingreso antes que propiamente una política migratoria?

Entiendo que cumplen funciones distintas una ley y una política, pero la ley se queda solamente con reglamentos, tipos de visa, distribución, etcétera, en los que los derechos están enunciados al principio, pero después quedan condicionados por los artículos que vienen a continuación, y no hay una estructura que permita una participación más real en la definición de la política, porque la ley establece dónde se va a definir la política, pero son restringidos los actores que van a participar en esa discusión. Por eso la ley, si bien no debiera hacerse cargo de la política, debiera establecer el mecanismo para que ese espacio sea lo más representativo posible. La ley, con el afán de que no se puedan modificar las visas adentro del país, deja cerrada la puerta para mecanismos permanentes de regularización, o sea, si es que uno tiene la convicción 
de situarse en la protección de los derechos humanos de los migrantes, eso requiere que las personas que están en el país puedan tener la posibilidad de regularizarse. La ley debe contemplar mecanismos para que la gente que no pueda lograr su regularización en primera instancia, sino que pueda lograrla en una segunda instancia, pero la respuesta de la ley para aquel que no logra regularizarse en primera instancia es la expulsión.

En relación con la propuesta vía indicación legislativa de crear un Servicio Nacional de Migrantes, ¿qué desafíos plantea su creación en cuanto institución reemplazante del Departamento de Extranjería y Migración (DEM)? ¿Considera que es un enfoque adecuado radicar sus labores en la Subsecretaría del Ministerio del Interior y Seguridad Pública?

El principal desafío es que tenga la categoría de servicio, y eso lo pondría teóricamente en una categoría mayor. Por supuesto que tiene que tener asociado un presupuesto considerable e implica también modernizar la atención, la posibilidad de vincularse con otros ministerios, establecer vínculos con desarrollo social. Es más amplio que el consejo actual.

En cuanto a la segunda pregunta, yo creo que, si la principal función del DEM es entregar las visas, sería muy raro y complejo que estuviese radicado en el Ministerio de Desarrollo Social. No me genera problema que esté dentro del Ministerio del Interior, en cuanto existan espacios de participación para la definición de la política que contemplen al Ministerio de Desarrollo Social, el Ministerio del Trabajo, el Ministerio de Salud, que son los encargados de la dimensión social de toda la migración y que ellos sí participen de la política. En cuanto a la entrega de visas, no sé si el Ministerio de Desarrollo Social lo podría hacer bien.

Ahora bien, el Ministerio del Interior no debiera ser la entidad encargada de la inserción de los migrantes. El proceso de inserción tiene que estar radicado de manera transversal en los distintos ministerios. El tema de las visas es ineludible y debe estar radicado en el Ministerio del Interior, pero si este ministerio no se va a encargar de los procesos de inserción e inclusión de la migración, tiene que haber un espacio donde se tomen políticas transversales, y ello tiene que estar coordinado con la entrega de visas. Esto requiere muchísima coordinación entre los distintos ministerios. Lo que tiene que estar muy claro es la forma de trabajo interministerial que permita que las decisiones que se tomen en la política migratoria tengan conexión con los distintos ámbitos de la vida de las personas.

De todas formas, hace ruido también que sea el Ministerio del Interior y Seguridad. Tampoco hay que olvidar la noción que tiene la seguridad. Entonces se suele asociar la 
migración como un problema de seguridad nacional, o como algo que viene a desestabilizar la seguridad del país

Por ejemplo, en el caso de Argentina en el siglo XIX estaba radicado en el Ministerio de Agricultura. Actualmente, en casi todos los países está radicado en los ministerios de Interior.

Ahora bien, es necesario entender cómo funciona el Estado y que la definición de la política de la ley migratoria tiene que ver con la construcción de los límites del Estado-nación. Entonces, si no fuera el Ministerio del Interior, y en su lugar se ocupase el Ministerio de Desarrollo Social, sería políticamente más complejo, porque supondría ponerle una noción de seguridad al Ministerio de Desarrollo Social que no tendría por qué tener, debido a que es imposible desligar la migración de la idea de construcción de Estado-nación y de la idea de ingreso, fronteras. Podríamos ser muy idealistas, pero en la política y el mundo real no creo que se pueda funcionar de otra manera, pero debe ser con los resguardos necesarios.

¿Qué desafíos para los derechos sociales de la educación, salud y seguridad social puede traer para el país el incremento migratorio que se está produciendo en los últimos años, en términos de protección de derechos?

Debe seguir luchándose por una igualdad de derechos en todas las dimensiones y ámbitos. En salud y educación creo que se ha avanzado en el acceso al derecho, y eso es de los logros que se pueden mostrar de la administración anterior. En educación es claro, porque todo niño por ser niño tiene acceso a la educación básica y media, no así a la educación universitaria. $Y$ en salud se les garantiza el acceso a salud independiente de su estatus migratorio, con todos los problemas que existen en la salud pública. Ése es el piso de partida y no nos podemos quedar ahí, porque de ahí para adelante tiene que ver con el desarrollo de la política pública, el cómo hacerse cargo de la diversidad que representa la migración. No basta con decir «todos tienen derecho a atenderse en el consultorio» si no tienes dispositivos que permitan adecuar la entrega de ese servicio a una realidad distinta con la que se ha lidiado en el pasado. Para los servicios, el principal desafío es adaptarse a un contexto distinto y entender que no es el migrante el que debe adaptarse a la forma en que se entrega el servicio, sino que tiene que haber un dialogo entre ambos y la institución también tiene que adaptarse, tiene que recoger las demandas específicas, reconocer que efectivamente hay otras enfermedades y que hay mapas epidemiológicos distintos según la zona geográfica. Nosotros no tenemos las mismas enfermedades que pueden existir en el trópico, pero hay que generar los mecanismos para poder detectarlas tempranamente, ponerse en contacto con los otros servicios de salud y averiguar cómo se tratan este tipo de enfermedades. Pero la soberbia ha sido muy grande y se piensa que se tiene todo el conocimiento y que se sabe cómo resolver todos los problemas. Enton- 
ces, falta mucho para flexibilizar y adecuar la entrega de servicio a esas realidades diferenciadas.

\section{Además del tema de las enfermedades, ¿ve otros nudos importantes?}

En educación, todo lo que tiene que ver en cómo formamos a los profesores, pues es muy distinto cuando el profesor hace clases con una idea homogénea del alumno. El profesor nunca recibe las herramientas para hacer clases en un curso en que el $70 \%$ viene de contextos distintos, y eso significa que trae historias distintas, vivencias distintas, usos del lenguaje distinto, construcciones traumáticas que pueden haber vivenciado los niños. Entonces, cómo se explica la pedagogía en una sala tan diversa y multicultural. Ése es un desafío para las universidades y cómo éstas forman a los docentes, y para los propios docentes y los colegios.

¿Cómo cree que el mercado laboral ha reaccionado ante esta situación? ¿Qué medidas se deberían adoptar con miras a resguardar sus derechos laborales?

Es importante la regularización, para que puedan estar en la misma situación que los chilenos, para poder exigir los mismos derechos que corresponden. Entonces, creo que el primer punto es apuntar a la regularización constante. Por eso, la ley debe contemplar mecanismos de regularización permanente, ya que la situación de irregularidad va a generar situaciones en las que se vulneren los derechos, que haya menos acceso, que haya más posibilidades de explotación. La regularización formal de la migración es el piso mínimo.

Estoy de acuerdo con que los procesos de regularización tienen que ser la excepción, porque es la prueba de que no está funcionando la ley, porque acá la principal irregularidad es producto de un tema administrativo, no de que la gente entre irregularmente. Entonces es el Estado el que no está siendo capaz de responder a la realidad migratoria, al poner una cantidad enorme de trabas, sumado a que ahora está totalmente desbordado, las colas son muy largas. Pero entonces, ¿quién produce la irregularidad? Es el Estado a través de este tipo de políticas. El Estado debe tener los mecanismos que se adecuen a esa realidad; si el objetivo es la regularización, entonces se debe adecuar la política para que la gente se pueda regularizar.

¿Cree usted que en esa paradoja hay cierto objetivo perverso? Porque eso genera mano de obra barata

No creo que sea perverso, puesto que no creo que haya alguien pensando en cómo generar más irregularidad, sino más bien que se inscribe en una contradicción del modelo económico que requiere trabajadores de manera permanente para poder incorporarlos en trabajos más informales, de manera que la política migratoria termina produciendo eso. 
Ello se cruza también con un discurso nacionalista y de seguridad que busca restringir la migración y, por otro lado, un mercado laboral con muchas ganas de beneficiarse de ese tipo de política porque sabe que queda en el borde mucha gente irregular, sin los papeles y que va a poder captar. Así, la política es funcional al mercado laboral; pero este discurso de seguridad, teñido de que está protegiendo los derechos, no creo que surja de personas que estén conscientemente haciéndolo. Sin embargo, así es como funciona la estructura social.

Sin embargo, es una realidad que la Sofofa y todas estas agrupaciones de empresarios pueden reunirse, sacar una resolución, tocar la puerta de la Moneda, puesto que tienen contacto directo, $y$ pedir: "Queremos una ley de migración», y no lo han hecho Los empresarios son mucho más liberales, y el planteamiento liberal lo que propone es que la movilidad es un factor beneficioso que, si funciona en los bienes materiales que se intercambian y en los flujos de dinero, funciona también en la mano de obra. Cuando se creó la Unión Europea, uno de los principales elementos fue la libre circulación de las personas, lo que era beneficioso para todo Europa, sobre todo teniendo en cuenta que el principal flujo migratorio en Europa no viene de afuera, sino que de adentro de la comunidad. Así, la libre circulación no se establece porque todos los europeos sean tan receptivos o tolerantes o porque quieran poder viajar sin fronteras, sino porque tiene en el mercado laboral su mayor aplicación.

Lo mismo ha ocurrido en Mercosur, en el que la dimensión laboral no estaba contemplada cuando se firmó el acuerdo constitutivo, pero rápidamente se entendió que se requiere la posibilidad de tránsito de los trabajadores. Por ello, después se acordó la libertad de movimiento de los trabajadores, de modo que hoy el chileno que quiere trabajar en Argentina solo necesita presentar una carta manifestando «me quiero quedar acá, vengo a trabajar» para obtener la residencia del Mercosur. Eso facilita la movilidad laboral, y está pensado desde ahí, no desde una integración, y eso lo empujan los empresarios, puesto que saben que es beneficioso.

Así las cosas, la discusión en Chile no es sobre si el empresariado se ha opuesto a un proyecto de ley o el que se ha opuesto a que haya movilidad de personas. De hecho, ocurre al revés, ya que ellos entienden que es muy beneficioso. Ahora, si no hay libertad transparente de personas, por lo menos que tengan disponibilidad de mano de obra, y disponibilidad de mano de obra en contextos restrictivos se traduce en trabajadores irregulares.

¿Qué rol cree que deberían desempeñar los medios de comunicación para abordar los actuales desafíos que representa el aumento de la población migrante en Chile? ¿Es necesaria una regulación de contenido más fuerte desde el Estado que contribuya a la integración? Lo anterior pensando en el Consejo Nacional de Televisión y la regulación de contenidos 
Esto depende del Estado, porque si vamos a tener una línea como la del gobierno de Sebastián Piñera regulando los contenidos, creo que no vamos a avanzar mucho.

Los medios tienen un rol tremendamente importante, pero deben tener una mirada más crítica, porque hoy lo que aparece es la asociación de la migración con la delincuencia, pobreza y con vulnerabilidad de derechos; y si bien se muestra igualmente una imagen positiva, ésta es la del migrante de esfuerzo. En definitiva, no hay una presentación de los migrantes como ciudadanos que tienen los mismos derechos y que deben tener los mismos derechos que todos nosotros. Entonces creo que tienen que educar mucho más en eso a la población local, y si bien ello es así, también existe mucho «eco». Este asunto es un «ida y vuelta», porque no es que los medios de comunicación sean un ente maligno que domina las conciencias de las personas, sino que hay también una opinión pública que es contraria a la migración. En este sentido, yo creo que, si haces una encuesta hoy, la mayoría querría que no hubiese migrantes o que se fueran, puesto que la opinión pública no está a favor de la migración. Entonces, los medios de comunicación y los políticos, que junto con la opinión pública son los tres actores relevantes en este tema, tratan de congraciarse con esta última. Los políticos lo hacen porque puede traducirse en votos en el futuro, y en consecuencia generan políticas más restrictivas, nacionalistas y populistas. Por otro lado, los medios de comunicación reproducen también un discurso político sin hacer una reflexión y sin entender que estos mitos no tienen antecedentes que los validen.

Hace falta educar a la población para entender que la migración es un factor de desarrollo que necesitamos. Falta una ley o procesos de inclusión en los que la diversidad sea un elemento central en esa inclusión, y en el que se asegure un principio de igualdad en el reconocimiento de la diversidad. Tienen mucho que educar a una opinión pública que es más bien reactiva y conservadora frente a la migración.

¿Usted cree que es necesaria una regulación fuerte de parte del Estado, o eso se podría generar desde otros mecanismos?

Me causa inquietud sostener que la regulación debiese ser más fuerte, porque lo más seguro es que sería nefasta. Por eso, más bien es necesario que se haga una reflexión. Ahora, cuando nos encontramos, por ejemplo, con programas con alto contenido de discriminación y xenofobia, por supuesto que debe haber una entidad que controle esto, que diga que ello no corresponde.

El problema aquí es que no tenemos entidades separadas, el Consejo Nacional de Televisión lo conforma gente nombrada por políticos. Si hubiera una entidad neutra e independiente $u$ otra forma de configurarlo, uno podría plantearlo. Pero hoy no hay mucha independencia, es decir, no hay un control real sobre los principales medios de comunicación. 
Usted señalaba que los medios de comunicación en general son una «caja de eco» de los prejuicios y resquemores de la población respecto de la migración, pero el sentido común tendería a pensar lo contrario: que el sentido común de la población está formado por los medios de comunicación

No creo que los medios sean una caja de resonancia. Existen tres actores que están presentes y se retroalimentan. Los medios sin duda que afectan, pero creo que el asunto es más complejo. Ciertamente en la opinión publica hay información que se extrae de los medios, pero también tiene que ver con experiencias personales, de, por ejemplo, la señora que fue al consultorio y le tocó esperar dos horas porque había más mujeres haitianas, lo cual es más bien experiencial, y eso llega después a los medios. Entonces va de ida y vuelta. Lo mismo ocurre con el discurso político, porque cuando en el discurso político se dice «vamos a poner visa a los haitianos porque no queremos que entren más haitianos», aunque no se diga con esas palabras, el efecto de ese mensaje es ése, y legitima completamente a la señora del consultorio para decirle a la mujer haitiana "váyase del país» y, a su vez, los políticos van a recoger la experiencia de esa señora y le van decir «tiene toda la razón, porque a mí me interesa su voto».

¿De qué manera ha impactado en el imaginario colectivo de la población chilena el cambio de población migrante de los últimos años? ¿Qué función tienen los estereotipos culturales en una integración de los migrantes? Esto pensando en el cambio de población migrante que se vivió, por ejemplo, desde un predominio peruano-argentino a uno venezolano-haitiano

La verdad es que no lo sé. No sé cuál es el imaginario colectivo de la población chilena sobre la población migrante y cuanto ha cambiado éste.

Es obvio que uno interactúa a partir de lo que tiene en la cabeza y las expectativas que tiene del otro y de cómo el otro se va a comportar. Uno no interactúa en el vacío, sino que cuando uno se encuentra con alguien inmediatamente identifica si es que es hombre, si es que es mujer, si es grande, bajo, si es chileno o extranjero; $y$ todo eso en fracciones de segundo determina el tipo de interacción. Entonces, claramente si hay una representación del migrante negativa, como, por ejemplo, del colombiano como narcotraficante, y te bombardean todo el tiempo con ella, uno se va a encontrar en la esquina con un colombiano $y$, aunque no lo quiera, va a tener ese contexto que va a determinar y predefinir la interacción que allí se desarrolle. Es imposible que no sea así, porque tenemos estereotipos de todo. Un hombre sabe lo que va a responder una mujer, cuando te acercas a una niña en una fiesta es porque tienes la expectativa de que si la invitas te va a decir que sí, y este ejemplo funciona por igual para todo. Por lo tanto, los estereotipos sí tienen una función en la forma en cómo se desarrolla una interacción, y si son estereotipos positivos o negativos tendrán una incidencia distinta, 
Así, si es que llega, por ejemplo, un alemán, se establece una interacción totalmente distinta que cuando llega una persona de Bolivia.

Ahora bien, aquello no es la determinante última en la interacción, pero lo que ocurre es que muchas veces nos quedamos con ese estereotipo, lo reproducimos $y$, en consecuencia, leemos todo desde ese estereotipo. Entonces, si la persona con que te encontraste hace cualquier cosa, vas a leer, o habrá más posibilidades de que leas ese gesto desde el estereotipo que tienes, con lo cual, a su vez, vas a reafirmarlo y va a costar más que salgas de ese estereotipo negativo. También puede ocurrir lo mismo si el estereotipo es positivo, y por eso cuesta tanto ver que, por ejemplo, gente de clase alta pueda robar, porque no tienes el estereotipo de que roban, y entonces puede ser que saludes a alguien del sector alto que vaya bien vestido y sientas que estás en confianza, cuando en realidad podría suceder que esa persona te quiera robar y no te des cuenta porque no va a estar dentro de tus expectativas. Siendo así, la interacción que estableces con esa persona no te va a poner en alerta. En cambio, si ocurre la misma situación con una persona de Haití, vas a estar alerta y todo lo que el otro haga lo vas a leer desde esa forma de representación, y eso hace que sea complejo salir de ahí.

Por ello, creo que el conocimiento mutuo de las personas, el aprender e incorporar un enfoque multicultural, el entender a las personas no desde un estereotipo, sino que en el contexto en que viene la otra persona, y querer realmente aprender a entender, nos permite salir de este otro tipo de relaciones. Es importante que en todo haya un enfoque multicultural, que sea transversal, que permita entender y dar sentido a las acciones. En el caso, por ejemplo, de los haitianos, debemos lograr entender cómo opera o cómo es Haití, situación que se dio un poco con el caso de Joane Florvil. Entender que, si la mamá deja a su bebé con el guardia, es porque confía en la autoridad, y ello es un contexto cultural que explica una práctica. Pero tenemos aquí otro contexto cultural que ve esa práctica desde otro lugar.

Un enfoque multicultural permite entender la práctica no desde el enfoque cultural de acá, sino desde el enfoque cultural de allá, implica tener que abrirse a entender cómo opera esa constelación de significados en la cultura de la otra persona.

Entre los discursos multiculturalistas encontramos una tendencia a entregar respuestas que promueven el respeto a la diversidad en la esfera privada, en perjuicio de un enfoque que reconozca la necesidad de una respuesta integral que también tiene que abarcar la esfera pública, lo que se ha entendido como «multiculturalismo débil» por algunos autores. En el contexto de Chile, donde la mayoría de los migrantes proviene de América Latina y no se presenta un choque cultural tan potente como en el caso, por ejemplo, de Europa y la migración musulmana, ¿qué medidas contribuirían a reforzar la respuesta multicultural para extenderla desde lo privado a lo público?

Son los derechos. La respuesta es el reconocimiento de derechos, porque ello signi- 
fica reconocimiento del principio de igualdad, de que todos somos iguales y de que todos los que vivimos en este territorio tenemos los mismos derechos. Eso es espacio público, es ciudadanía y construcción de ciudadanía. Entonces, debemos salir del reconocimiento multicultural de valorar la diversidad cultural, porque en el fondo eso es puro multiculturalismo débil - lo que está bien pero no es el foco de atención-, y poner el foco de atención en que todos tenemos derecho a educación, a salud, a trabajar en condiciones dignas, etcétera.

Y también tenemos derecho participar de la comunidad local. No se trata de «tú te incorporas a mí según como yo veo las cosas», sino que "en conjunto construimos algo distinto» y participamos en organizaciones sociales, en la comunidad, en el municipio, etcétera. Se trata de que todos los grupos puedan contribuir al desarrollo de esa comunidad local en igualdad de condiciones, y no unos como minoría y otros como cultura dominante, pero eso supone descentralizar la posición de privilegio que tiene la cultura dominante de sentir que nosotros sabemos hacer las cosas y que ellos tienen que aprender cómo las hacemos, o de que, en el fondo, «yo te autorizo a ser distinto».

¿Cree usted que es posible encontrar una respuesta a los problemas que conlleva la migración moderna al interior del mismo modelo económico y político que le dio sustento para aparecer?

Es que no queda otra opción, puesto que el modelo económico no va a cambiar mucho. Idealmente podemos sacar más leyes que intenten regularlo, pero no veo por dónde cambiar el modelo económico. Creo que la pregunta es más bien por el desafío que tiene hoy día el modelo económico y político para incluir, integrar e incorporar la migración entendiendo que la migración es un factor de globalización, y que no es algo de lo que los Estados puedan prescindir.

En consecuencia, el desafío tiene más que ver con la construcción actual, puesto que, por ejemplo, en el siglo XIX se iba a buscar migrantes afuera. América Latina lo hacía y nunca se vio como un problema. Pero ocurrió que, en el siglo XX, a partir de los años setenta, se empieza a ver como un problema relacionado con muchas otras razones. Así, el desafío que tienen todas las sociedades es descubrir cómo avanzar en procesos de integración, de inclusión y de representatividad, porque la migración transforma las sociedades. La sociedad ya no es homogénea sino heterogénea, y esa heterogeneidad tiene que ser parte de la construcción de la nación. Hasta hace poco las naciones se entendían mucho más homogéneas en términos de su población. Por ejemplo, «Francia era para los franceses», y esto lleva a tratar de recuperar la idea de un «francés ideal», $y$ te aseguro que el promedio de los franceses es una mezcla gigantesca. Entonces, la pregunta que hay que hacerse es cómo se incorpora todo eso en el discurso político en la construcción del Estado-nación. 
Otra respuesta que a mí me surge es que probablemente los problemas de la migración no tienen una solución efectiva y feliz en el contexto de la economía actual

Es que ya lo ha habido en el pasado. En Estados Unidos, hasta los años setenta, década de la crisis del petróleo, en general existió una forma de abordar la migración -aunque por supuesto que hay un proceso de adaptación-. En el imaginario norteamericano, la llegada de gente de muchos lugares significaba la conformación de un país de inmigración, lo que no generó ruido sino hasta cierto momento. En Europa, por su parte, se llevó una gran cantidad de migrantes de fuera del territorio para poder cumplir, y tampoco era problema. Entonces, ¿por qué es problema hoy?, ¿qué es lo que lo transforma en crisis? ¿Las crisis económicas? Al final, el migrante termina siendo el chivo expiatorio de un montón de transformaciones de un modelo económico que deja a las personas con menos empleo y con menos beneficios sociales, $y$ entonces se encuentra a este actor como el perfecto chivo expiatorio de todos estos males, y ahí aparecen los discursos nacionalistas diciendo: «Vamos a sacar a todos los migrantes y se van a acabar todos los problemas», lo que es un gran mentira.

Igualmente, quiero creer que los países, las sociedades y las personas tenemos que buscar formas para así avanzar, y entiendo que probablemente éste va a ser de los grandes desafíos del siglo XXI, pero vamos a tener que aprender a lidiar con eso y encontrar soluciones.

Existe un consenso en cuanto a que flujos migratorios elevados generan un impacto negativo en las condiciones laborales de los trabajadores del país receptor, situación que, en Chile, por la marginal tasa de extranjeros en el mercado laboral, todavía no se ha materializado. ¿Ve al respecto un conflicto en potencia en el Chile de hoy? ¿Cómo enfrentarlo para que no llegue a situaciones de violencia?

Primero, estoy de acuerdo en que el aumento de la migración no ha generado problemas en las condiciones laborales. Anteayer escuchaba a Joseph Ramos, que mencionaba un estudio en el cual se señalaba que el salario promedio no había bajado con la migración; de hecho, había subido. Entonces yo no veo por dónde pueda haber un problema. El problema de la cesantía no pasa por la migración, pasa por las decisiones económicas y políticas. Ahora, si se puede transformar esta percepción en una potencial situación de conflicto o de violencia, sí, podría ocurrir si es que los políticos avivan esto. Creo que ese tipo de conflictos es más político que real, entonces si es que aparece y se acentúa esta visión, de que los migrantes traen problemas, enfermedades, de que traen sida, etcétera, claro que va a provocar un conflicto, pero ello va a ser producto de discursos que vienen de determinados actores políticos interesados en exacerbarlo. 


\section{Sobre los autores}

Abril Silva es estudiante de Derecho de la Universidad de Chile, pasante del Centro de Derechos Humanos de la misma universidad y asistente editorial del Anuario de Derechos Humanos.

Benjamín González es estudiante de Derecho de la Universidad de Chile, pasante del Centro de Derechos Humanos de la misma universidad y asistente editorial del Anuario de Derechos Humanos. 
